\title{
PERCEPÇÕES SOBRE OS DESAFIOS DA DOCÊNCIA E ATUAÇÃO DOS ESTUDANTES COMO GESTORES DA APRENDIZAGEM: UM ESTUDO DE CASO
}

\author{
Rebeca Sá do Nascimento Carrazzoni ${ }^{1}$ \\ Patrícia Lacerda de Carvalho ${ }^{2}$
}

\begin{abstract}
RESUMO
A educação no Ensino Superior enfrenta novos formatos que conferem novos papéis para os atores envolvidos no processo de ensino-aprendizagem, o docente e o discente. Assumir os desafios enfrentados, transformando a postura da educação tradicional passiva pela postura ativa na busca pelo conhecimento, autonomia e protagonismo do aprendiz tornou-se uma discussão recorrente no ambiente educacional. Sendo assim, este capítulo se propôs a analisar o papel desempenhado pelo docente e pelo discente na nova configuração do ensino superior, a partir da aplicação da metodologia ativa Caso para Ensino para 32 alunos do curso de Administração. A pesquisa aplicada de abordagem qualitativa utilizou a observação participante e o estudo de caso único para analisar o contexto. $\mathrm{O}$ caso para ensino foi o método para identificar as possibilidades das metodologias ativas na transformação do conhecimento. O relato da experiência, a reflexão crítica sobre os papéis assumidos e a aprendizagem na ação foram pautas da análise. Conclui-se que a educação mudou e os papéis também mudaram, sendo necessária uma nova configuração na educação superior, cuja sugestão do capítulo enfatiza as metodologias de ensino como caminho aplicável.
\end{abstract}

Palavras-chave: Docência. Aprendizagem. Metodologias Ativas. Caso para Ensino.

\section{INTRODUÇÃO}

O conhecimento é um aspecto imprescindível para o desenvolvimento humano e da sociedade. As formas de adquirir o conhecimento foram se transformando ao longo da história a partir da evolução das interações e interesses dos seres humanos. Essas modificações, cada vez mais ágeis e impactantes, geram obsolescência de estruturas e sistemáticas comumente utilizadas, mudando assim, o modo de aprender. Nesse contexto, o conhecimento não é algo estático, mas dinâmico, que atualmente vem exigindo competências dos professores e alunos para que o ambiente educacional seja criativo, inovador e promova a colaboração para resultar no aprendizado (BITTENCOURT, 2016).

O debate atual acerca da educação superior em conjunto com o ambiente educacional levanta questões importantes, já que é sabido que o mercado de trabalho exige uma postura ativa e dinâmica dos profissionais, orientados para as constantes mudanças e disposição para

\footnotetext{
${ }^{1}$ Mestra e Doutoranda em Administração no Programa de Pós-Graduação em Administração da UFPB. E-mail: rebecasa.nascimento@gmail.com

${ }^{2}$ Mestra e Doutoranda em Administração no Programa de Pós-Graduação em Administração da UFPB. E-mail: patricialacerdac@gmail.com
} 
buscar o aprendizado continuamente. Dessa forma, torna-se incoerente o conteúdo engessado baseado na tradicionalidade. Isto conduz o ensino a integração do aprofundamento técnicocientífico e teórico com a prática e aprendizagem dinâmica, preparando o aluno para situações reais após a formação (ESCRIVÃO FILHO; RIBEIRO, 2008).

Diante das novas exigências da educação, questiona-se o papel do professor e do aluno, ambos com suas novas funções ante aos novos formatos de discussão dos saberes para sedimentação do conhecimento. A visão antiga de que o professor é o centro da sala, colocado em um degrau acima porque é detentor do conhecimento, perde espaço para a desafiadora percepção de que os alunos possuem uma atuação ativa e autônoma para proporcionar seu próprio aprendizado, sendo este mediado pela experiência (ARAÚJO et al., 2014).

O ensino superior demanda uma preparação do docente, muitas vezes, ausente nas formações de pós-graduação, a didática e o contato com novas metodologias de ensino exigem um esforço pessoal deste profissional. Buscar aliar a teoria e prática é um assunto recorrente que, segundo Araújo et al. (2014), está sujeito à premissa de um aprendizado direcionado ao processo experiencial e a ação na formação docente. Ademais, os autores ressaltam a importância de estratégias de ensino que estimulem o ambiente propício ao pensamento reflexivo e senso crítico para a evolução dos conhecimentos e aprendizagem.

Com base no exposto, o capítulo se propõe a analisar o papel desempenhado pelo docente e pelo discente na nova configuração do ensino superior, a partir da aplicação da metodologia ativa Caso para Ensino. Diversos estudos demonstram essas ressignificações no modo de ensinar e aprender, novos papéis dos atores e resultados melhores (SONAGLIO; GODOI; LIMA; SILVA, 2013; ARAÚJO, 2014; BITTENCOURT, 2016; SALVADOR; IKEDA, 2019).

\section{ENSINO SUPERIOR: OS PAPÉIS ASSUMIDOS}

O ambiente da docência é desafiador, nesse sentido o professor precisa estar atendo às mudanças na sociedade, tanto em dimensões técnicas como humanas, visando estar apto a construir conhecimento em cada circunstância que a profissão irá lhe exigir, visto que atualmente a ênfase está na formação permanente com o foco no ensino-aprendizagem do aluno.

Em se tratando de ensino, o centro é o docente, já na aprendizagem o centro é o aluno. Diante disso, busca-se que não exista um "centro", mas sim que ambos atuem como coautores na construção do ensino-aprendizagem. Dessa forma, o docente deixa de centralizar e transmitir as informações que os alunos devem conhecer para tornar-se um elemento que contribui para a construção do conhecimento. 
Segundo Bittencourt (2016), o ensino superior sustentou a tradicionalidade do conhecimento dissociado da realidade mercadológica por muito tempo. Nesse contexto, "em quatro situações são perceptíveis as mudanças no ensino superior: no processo de ensino, no incentivo à pesquisa, na parceria e coparticipação entre professor e aluno no processo de aprendizagem, e no perfil docente. Assim, se exige cada vez mais do docente. A competência pedagógica do docente de ensino superior transcorre pela formação simultânea com o mundo do trabalho, teoria e a prática, com o objetivo de fazer da sala de aula um ambiente vivo e real (MASETTO, 2012, p. 23).

A educação se transformou por meio do emprego de diferenciadas técnicas e metodologias de ensino, divergindo do processo tradicional que preconiza a memorização. A necessidade de aulas baseadas em métodos e dinâmicas de aprendizagem distintas do modelo de aulas expositivas e passivas demanda do docente e do discente uma nova postura frente ao conhecimento, a partir de processos de ensino-aprendizagem mais colaborativos, reflexivos, críticos, criativos e inovadores (BITTENCOURT, 2016; SALVADOR; IKEDA, 2019).

O espaço educacional exige que o docente detenha competência na área do conhecimento que leciona, domínio na área pedagógica, propriedade na área política, desenvolvimento de habilidades na área afetivo-emocional e, ainda, habilidades humanas e profissionais. Sendo assim, “o ofício do professor só acontece quando exercemos nossa docência com profissionalismo, isto é, de forma competente e cidadã" (GAETA; MASETTO, 2013, p. 103).

Nesse contexto, Masetto (2012, p. 55) apresenta quatro integrantes do processo de aprendizagem no ensino superior: "os professores, os alunos, o monitor e a direção". O professor pode atuar de várias maneiras no processo, unindo-se a seus pares, objetivando dar maior significado aos assuntos selecionados a serem ministrados em determinada disciplina, observando o que os alunos já tiveram oportunidade de estudar, priorizando os assuntos que serão novidades para turma, mesclando assuntos de várias disciplinas que se complementam, ajudando em um melhor entendimento, entre outros mecanismos. Enfim, o professor exerce um papel de ponte entre o aprendiz e o aprendizado, operando como mediador pedagógico, trabalhando junto com os alunos.

O monitor vem fortalecer a interação "professor - aluno" e "aluno - professor", sendo um importante colaborador para o diálogo existente entre as partes e atuando como um facilitador na disciplina em questão. O aluno vem atuar na interaprendizagem, sendo fundamental nesse processo. Muitos alunos têm dificuldade de aprender com o professor e aprendem com os colegas, por meio de atividades em grupo ou grupos de estudos. 
Por fim, a direção, que atua apoiando, possibilitando recursos e cobrando resultados dos outros participantes, buscando gerenciar se o processo de aprendizagem de fato está acontecendo, geralmente por meio de indicadores como nota, avaliação dos professores, necessidades dos alunos, entre outros. Sendo importante destacar que existem outros participantes nesse processo, como: servidores técnicos, colaboradores, entre outros.

De fato, a educação dinâmica e inovadora mostra-se necessária para o aprendizado e desenvolvimento de capacidades e habilidades. Segundo Bittencourt (2016), a aprendizagem ativa acompanha a rapidez das mudanças na sociedade do conhecimento e refere-se ao processo de análise, síntese e solução de problemas para gerar conhecimento ativamente de forma colaborativa. Esse tipo de envolvimento é proporcionado por atividades experimentais, solução de problemáticas, colaboração e aprendizagem experiencial.

\section{APRENDIZAGEM EXPERIENCIAL: CASO PARA ENSINO COM METODOLOGIA ATIVA}

Existem pessoas que se sentem mais produtivas observando, enquanto outras preferem teorizar e/ou experimentar, o que define os estilos de aprendizagem individuais. Entretanto, esse processo de seleção pode ocorrer com o docente que acaba priorizando o estilo de sua preferência. No entanto, ao focalizar em um único método específico de aprendizagem, o docente não é capaz de atuar como facilitador para os aprendizes. Faz-se necessário compreender as múltiplas linguagens utilizadas para alcançar a utilização das distintas metodologias disponíveis para contribuir para o aprendizado efetivo. Desse modo, o docente poderá, verdadeiramente, assumir o papel de mediador e aprendiz no processo, colaborando com a aprendizagem de forma direta.

Ressalta-se que o processo de aprendizagem precisa dos múltiplos fatores para se concretizar, a exemplo do planejamento, atuação, postura, empatia e colaboração, que são etapas essenciais para construção do alicerce da aprendizagem. Portanto, torna-se fundamental conhecer e compreender quais as metodologias ativas de ensino e como se aplicam, conforme elencadas no Quadro 1.

Quadro 1 - Exemplos de Metodologias Ativas e suas características

\begin{tabular}{|c|l|c|}
\hline $\begin{array}{c}\text { Metodologias } \\
\text { Ativas }\end{array}$ & \multicolumn{1}{c|}{ Características das Metodologias Ativas } & Referências \\
\hline $\begin{array}{c}\text { Aprendizagem } \\
\text { baseada em } \\
\text { problemas }\end{array}$ & $\begin{array}{l}\text { Pressupõe a cooperação em pequenos grupos, conduzida } \\
\text { por um tutor, com um estudo autodirigido, para } \\
\text { proporcionar uma educação multidisciplinar e } \\
\text { avaliações progressivas. }\end{array}$ & $\begin{array}{c}\text { Neto, } \text { et al. } \\
(2017)\end{array}$ \\
\hline Casos para ensino & $\begin{array}{l}\text { Abrange um relato de uma situação vivenciada por um } \\
\text { profissional, uma organização, ou ainda um projeto }\end{array}$ & $\begin{array}{c}\text { Alberton e } \\
\text { Silva (2018) }\end{array}$ \\
\hline
\end{tabular}




\begin{tabular}{|c|c|c|}
\hline & $\begin{array}{l}\text { específico de natureza prática e/ou social, que apresenta } \\
\text { um dilema a ser analisado no contexto do ensino. }\end{array}$ & \\
\hline Estudo de caso & $\begin{array}{l}\text { Os estudantes aprendem à medida que analisam as } \\
\text { situações apresentadas nos casos e desenvolvem um } \\
\text { plano de ação para resolver as causas fundamentais dos } \\
\text { problemas expostos. }\end{array}$ & $\begin{array}{l}\text { Machado e } \\
\text { Callado } \\
\text { (2008) }\end{array}$ \\
\hline Estudo dirigido & $\begin{array}{l}\text { Tem como enfoque a participação ativa dos alunos, tais } \\
\text { como: leitura, interpretação, comparação, avaliação, } \\
\text { análise e elaboração de textos construídos a partir do } \\
\text { contexto estudantil. }\end{array}$ & $\begin{array}{l}\text { Gabriel, Silva } \\
\text { e Freire } \\
\text { (2018) }\end{array}$ \\
\hline $\begin{array}{l}\text { Estudo do } \\
\text { meio/campo }\end{array}$ & $\begin{array}{l}\text { Consiste no estudo direto do contexto natural e social no } \\
\text { qual o aluno se insere. Auxilia na realidade, observação } \\
\text { e comunicação, como também ressalta uma realidade } \\
\text { para além da sala de aula. }\end{array}$ & $\begin{array}{l}\text { Lestinge e } \\
\text { Sorrentino } \\
\quad(2008)\end{array}$ \\
\hline Estudo do texto & $\begin{array}{l}\text { Como desenvolver? Análise textual; Análise Temática; } \\
\text { Análise Interpretativa; Problematização; ou, Síntese } \\
\text { (reelaboração da mensagem com base na reflexão } \\
\text { pessoal). }\end{array}$ & $\begin{array}{l}\text { Gabriel, Silva } \\
\text { e Freire } \\
\text { (2018) }\end{array}$ \\
\hline $\begin{array}{l}\text { Explosão de } \\
\text { ideias } \\
\text { (brainstorming) }\end{array}$ & $\begin{array}{l}\text { Técnica de geração de ideias, que pode ser utilizada de } \\
\text { uma maneira disciplinada de geração de novas ideias a } \\
\text { partir de discussão entre os participantes; onde a } \\
\text { liberdade é dada a todos os integrantes do grupo. }\end{array}$ & $\begin{array}{l}\text { Tobias, } \\
\text { Faleiro e } \\
\text { Mello Braga } \\
(2017)\end{array}$ \\
\hline Fórum & $\begin{array}{l}\text { Debate livre de ideias, apresentações esquematizadas, } \\
\text { presença de um coordenador/moderador cuja parte final } \\
\text { é a das perguntas. O Fórum promove construções } \\
\text { colaborativas com valorização da subjetividade no } \\
\text { diálogo efetivado. }\end{array}$ & $\begin{array}{l}\text { Gonçalves, } \\
\text { Cunha e Sales } \\
\quad(2016)\end{array}$ \\
\hline $\begin{array}{l}\text { História em } \\
\text { quadrinho }\end{array}$ & $\begin{array}{l}\text { Os processos de codificação e decodificação que os } \\
\text { alunos experimentam na criação e interpretação de } \\
\text { quadrinhos se tornam elementos facilitadores do } \\
\text { aprendizado, porque há uma necessidade de } \\
\text { concentração. }\end{array}$ & $\begin{array}{l}\text { Silva, Santos } \\
\text { e Bispo } \\
\quad(2017)\end{array}$ \\
\hline Júri simulado & $\begin{array}{l}\text { Apresenta-se com o formato de uma sessão do tribunal } \\
\text { de júri, com algumas adaptações para o desenvolvimento } \\
\text { enquanto atividade pedagógica de forma que favoreça o } \\
\text { entendimento dos alunos e o desenvolvimento da } \\
\text { argumentação no aluno. }\end{array}$ & $\begin{array}{l}\text { Real e } \\
\text { Menezes } \\
(2007)\end{array}$ \\
\hline Mapa conceitual & $\begin{array}{l}\text { Ampliam a possibilidade de os estudantes se valerem de } \\
\text { recursos pessoais favoráveis para refletir e compreender } \\
\text { seus percursos de aprendizagem. }\end{array}$ & $\begin{array}{l}\text { Souza e } \\
\text { Burochovitch } \\
(2010)\end{array}$ \\
\hline Música & $\begin{array}{l}\text { Esse recurso implica considerar aspectos como a letra, a } \\
\text { melodia, o estilo, o ritmo, o volume, entre outros. A } \\
\text { música pode provocar a imaginação, a reflexão, } \\
\text { associações, pensamentos metafóricos. }\end{array}$ & $\begin{array}{l}\text { Vergara } \\
(2003)\end{array}$ \\
\hline $\begin{array}{l}\text { Produção de } \\
\text { vídeo-aula }\end{array}$ & $\begin{array}{l}\text { Os vídeos pedagógicos atraem os alunos, aproximando a } \\
\text { sala de aula do cotidiano e das linguagens de } \\
\text { aprendizado e comunicação da sociedade. A produção } \\
\text { de vídeos é uma ótima forma de expressão e } \\
\text { comunicação. }\end{array}$ & $\begin{array}{l}\text { Silva e } \\
\text { Oliveira } \\
(2018)\end{array}$ \\
\hline $\begin{array}{l}\text { Seminário } \\
\text { dinâmico }\end{array}$ & $\begin{array}{l}\text { Seminário em que todos os alunos se envolvem visando } \\
\text { oportunizar o desenvolvimento de vários papéis, como } \\
\text { avaliador, questionador, crítico, apresentador, entre } \\
\text { outros. }\end{array}$ & $\begin{array}{l}\text { Santos, Bastos } \\
\text { e Coelho } \\
\text { (2016) }\end{array}$ \\
\hline Stop motion & $\begin{array}{l}\text { Técnica de animação na qual o animador trabalha } \\
\text { fotografando objetos, fotograma por fotograma, em } \\
\text { outras palavras quadro a quadro. Entre um fotograma e } \\
\text { outro, o animador muda a posição do objeto, da forma } \\
\text { mais minuciosa possível, para que o filme nos dê a ilusão } \\
\text { de que o objeto está se movimento. }\end{array}$ & $\begin{array}{l}\text { Kaminski } \\
(2010)\end{array}$ \\
\hline
\end{tabular}

Fonte: Elaborado pelas autoras. 
A discussão a respeito da aprendizagem deriva de diversas correntes filosóficas com bases ontológicas e epistemológicas distintas, demonstrando a construção do seu conhecimento. A aprendizagem experiencial se direciona a implantar na educação tradicional os dados práticos da profissão, ultrapassando o sentido do "aprender fazendo" para enfatizar a utilização de processos cognitivos, motivacionais e emocionais, no qual os alunos executam atividades reflexivas sobre o que estão realizando e que tenha significado (BITTENCOURT, 2016).

Para o autor supracitado, a visão da aprendizagem ativa envolve o processo de ensino centrado na aprendizagem, métodos ativos para proporcionar a prática, transformação no papel assumido pelo docente e pelo discente, a metacognição e autorregulação da aprendizagem e a autonomia. Nesse contexto, a aprendizagem experiencial está inserida na aprendizagem ativa como um braço de suas possibilidades.

De acordo com Kolb (1984, p.41), a aprendizagem experiencial se refere ao "processo pelo qual o conhecimento é criado através da transformação da experiência". O ambiente real é o pano de fundo para a reflexão do aprendiz sobre a situação posta, de modo que ao final o mesmo tenha gerado experiências e significados emancipatórios. Com base nisso, a aprendizagem em ação preconiza o livre engajamento no delineamento de soluções de problemas instigantes que não possuem decisões programadas, propiciando o desenvolvimento pessoal por meio do processo reflexivo sobre a ação (O’NEIL; MARSICK, 2007).

Desse modo, o método de caso para ensino apresenta-se como uma metodologia ativa que pode proporcionar a aprendizagem experiencial, visto que este é tido como a junção de técnicas e ferramentas para acelerar experiências e por meio de sua resolução o conhecimento é construído (ALBERTON; SILVA, 2018). De acordo com os autores, a aprendizagem experiencial para o caso para ensino ocorre pela aprendizagem em ação, auxiliando no processo educacional de gestão e promovendo as estratégias ativas para uso pelos docentes. Para Ikeda, Veludo-de-Oliveira e Campomar (2006, p. 147), método do caso "é uma estratégia de ensino baseada na apresentação de circunstâncias factíveis e/ou verídicas com o objetivo de levar os alunos a refletirem sobre decisões para o episódio estudado".

O caso para ensino constitui-se em uma descrição de uma situação gerencial detalhada que demonstra a complexidade real das organizações para posterior tomada de decisão em ambiente controlado (ALBERTON; SILVA, 2018). O dilema apresentado pelo caso promove aprendizagem a partir das discussões em colaboração em busca de uma resposta que não é 
predeterminada. De acordo com os autores, esse método enfoca em uma situação real que pode ser vivenciada na profissão, em qualquer tipo de organização.

Sendo assim, percebe-se que o método pode gerar experiências enriquecedoras para o discente permitindo o desenvolvimento por meio das decisões tomadas, interação com outros aprendizes e reflexão sobre a ação. Com isso, o processo de ensino aprendizagem é modificado por meio das transformações exigidas pelos métodos ativos, tornando o discente protagonista da construção do seu conhecimento e ressignificação dos conteúdos e conceitos a partir de uma situação real. O docente assume uma nova postura mais moderadora e a este compete o esforço de se preparar para os novos desafios.

\section{METODOLOGIA}

O trabalho caracteriza-se como uma pesquisa de natureza aplicada e abordagem qualitativa, por meio da utilização do método de observação participante e estudo de caso único (YIN, 2015), com o objetivo de analisar o papel desempenhado pelo docente e pelo discente na nova configuração do ensino.

O meio escolhido para verificação no campo constitui-se no método de caso para ensino, cujo planejamento e aplicação eram de domínio das pesquisadoras e autoras. Para tanto, foi realizada a aplicação do caso em uma turma do curso de Administração, de uma instituição privada de ensino superior em João Pessoa, na Paraíba, considerando o livre acesso às turmas devido ao vínculo de trabalho de uma das pesquisadoras.

A disciplina que serviu de campo para esta pesquisa foi a de "Empreendedorismo", no $3^{\circ}$ período do curso no ano 2018, segundo semestre, entre os meses de agosto e dezembro e era formada por 32 discentes. A referida disciplina exigia uma visão mais ampla dos alunos quanto a organização, esclarecendo que o empreendedor necessitava treinar a sua percepção sistêmica e agir com inovação e diferenciação no mercado.

Com o intuito de operacionalizar o método, um planejamento foi elaborado por meio do plano de aula. Em seguida, de acordo com o tema específico da aula, selecionou-se um caso para ensino "CASA FLOR. UM CASO DE EMPREENDEDORISMO EM PEQUENO NEGÓCIO”, publicado na Revista de Administração e Inovação, elaborado por Souza e Fracasso (2008).

A aplicação ocorreu em um dia comum de aula, dentro do horário de duas horas, com a participação de todos os alunos por ser uma atividade avaliativa. A experiência está relatada na próxima seção com base na observação e participação das pesquisadoras e a partir dos relatos 
voluntários promulgados pelos discentes. A experiência foi gravada (com consentimento dos discentes) e revisitada para análise e descrição da aplicação do caso.

\section{DISCUSSÃO DOS RESULTADOS}

A seguir, o relato da experiência da aplicação do método de caso para ensino será descrito divido em fases, com base nas percepções das pesquisadoras participantes, destacando as interações, reflexões e ressignificação vivenciada pelos docentes e discentes no processo de ensino e aprendizagem experiencial.

\section{Fase 1 - Planejamento da aplicação do método}

Inicialmente, houve a elaboração de um plano de aula para organização da aplicação do referido caso. A distribuição do tempo e delimitação das atividades e entregas era essencial para o alcance do objetivo final. A intenção era proporcionar uma experiência que se aproximasse da realidade, promovendo a discussão dos pontos chaves e relacionando-os com a teoria discutida em sala de aula. Além disso, a reflexão deveria ser incentivada a partir da ação. $\mathrm{O}$ plano está exposto no Quadro 2.

Quadro 2-Plano de aula

\begin{tabular}{|c|c|}
\hline \multicolumn{2}{|c|}{$\begin{array}{l}\text { Tema da aula: } \mathrm{O} \text { empreendedorismo e o negócio: conceitos gerais sobre empreendedorismo } \\
\text { e empreendedor, características atitudes empreendedoras, oportunidades de } \\
\text { negócios e classificação do empreendedorismo. }\end{array}$} \\
\hline \multicolumn{2}{|c|}{ 1. Objetivos } \\
\hline \multicolumn{2}{|c|}{$\begin{array}{l}\text { Objetivo Geral: } \\
\text { - Explorar as teorias relacionadas ao empreendedorismo, possibilitando aos alunos o } \\
\text { desenvolvimento de habilidades por meio da aplicação dos conhecimentos absorvidos em } \\
\text { uma situação simulada, mediante caso para ensino, bem como a relação entre as temáticas } \\
\text { aprendidas para aprimoramento de análise crítica. }\end{array}$} \\
\hline \multicolumn{2}{|c|}{$\begin{array}{l}\text { - Discutir dilemas e pontos chave destacados no caso; } \\
\text { - Discernir sobre as escolhas realizadas e as possibilidades de alternativas; } \\
\text { - Consolidar os conhecimentos absorvidos por meio da construção de uma visão sistêmica } \\
\text { mediante a relação entre as temáticas abordadas no caso. }\end{array}$} \\
\hline $\begin{array}{l}\text { Competências } \\
\text { - } \quad \text { Desenvolv } \\
\text { - } \quad \text { Diagnostic } \\
\text { - } \quad \text { Negociar } \\
\text { - } \quad \text { Integrar e }\end{array}$ & $\begin{array}{l}\text { senvolvidas: } \\
\text { visão crítica e analítica; } \\
\text { a situação apresentada; } \\
\text { iiões diante e diferentes perspectivas e análises; } \\
\text { acionar teorias com a realidade organizacional. }\end{array}$ \\
\hline \multicolumn{2}{|l|}{ 2. Metodologi } \\
\hline \multicolumn{2}{|r|}{ com a explicação da metodologia e as fases para aplicação. } \\
\hline 10 minutos & $\begin{array}{l}\text { ação dos grupos, uma breve explanação é feita } \\
\text { ná-los para a discussão em pequenos grupos, } \\
\text { postas pessoais. }\end{array}$ \\
\hline
\end{tabular}




\begin{tabular}{|c|c|}
\hline 30 minutos & $\begin{array}{l}\text { - Os alunos discutem em pequenos grupos de } 4 \text { alunos as suas percepções } \\
\text { quanto ao caso e a situação apresentada. }\end{array}$ \\
\hline 5 minutos & $\begin{array}{l}\text { - As professoras fazem uma análise do caso, destacando conceitos vistos } \\
\text { em sala para estimular o pensamento crítico. }\end{array}$ \\
\hline 60 minutos & $\begin{array}{l}\text { - Com base nas questões disponibilizadas e respondidas pelos alunos, as } \\
\text { professoras iniciam a discussão no grande grupo. Na mesma posição na } \\
\text { qual se encontravam em grupo, é solicitado que os mesmos expliquem o } \\
\text { que observaram no grupo, se houve divergências e quais as opiniões. } \\
\text { - As professoras procuram não responder nada e pedir que os próprios } \\
\text { alunos discutam as visões dos colegas. }\end{array}$ \\
\hline 15 minutos & $\begin{array}{l}\text { - Fechamento da discussão, relacionando as observações com a teoria; } \\
\text { - Percepção e opinião dos alunos quanto a aplicação e aprendizagem. }\end{array}$ \\
\hline \multicolumn{2}{|l|}{ 3. Conteúdo } \\
\hline \multicolumn{2}{|c|}{$\begin{array}{l}\text { 1. Empreendedorismo: conceitos gerais, configurações e tipos; } \\
\text { 2. Empreendedor: conceitos, características e comportamento; }\end{array}$} \\
\hline \multicolumn{2}{|c|}{ 4. Avaliação da aprendizagem } \\
\hline \multicolumn{2}{|c|}{$\begin{array}{l}\text { Instrumento } \\
\text { - } \quad \text { Caso para ensino; } \\
\text { - Folha de respostas. }\end{array}$} \\
\hline \multicolumn{2}{|c|}{ 5. $\quad$ Recursos Didáticos } \\
\hline \multicolumn{2}{|c|}{$\begin{array}{l}\text { - Folhas de resposta; } \\
\text { - Lápis para quadro branco e apagador; }\end{array}$} \\
\hline \multicolumn{2}{|c|}{ 6. Referências } \\
\hline \multicolumn{2}{|c|}{$\begin{array}{l}\text { DORNELAS, J. C. A. Empreendedorismo: Transformando Ideias em Negócios. } 2 \text { ed. Rio de } \\
\text { Janeiro: Campus, } 2014 \text {. } \\
\text { SCHNEIDER, Elton Ivan. A caminhada empreendedora: a jornada de transformação de } \\
\text { sonhos em realidade. Editora Curitiba: InterSaberes, } 2012 \text {. }\end{array}$} \\
\hline
\end{tabular}

Fonte: Elaborado pelas autoras, 2018.

Orientadas pelo plano, as pesquisadoras buscaram por casos que expressassem o conteúdo de maneira clara e objetiva, retratando-o com base em uma situação problema factível e solucionável pelos alunos.

Para a escolha do caso Casa Flor, em análise, percebeu-se que este era escrito em forma de diálogo, mas também apresenta seções de explicação e descrição. Faz-se importante destacar a facilidade da leitura e número de páginas suficiente e adequado (pontos destacados como positivo pelos alunos). A preocupação com receptividade do caso era persistente devido ao fato de ser a primeira experiência dos alunos com aquela metodologia, portanto a intenção era de compreensão e estímulo à discussão.

Nesse sentido, o dilema a ser resolvido pelos alunos era claro, a trama simples e de fácil entendimento proporcionaria uma associação instantânea com os temas abordados. O interesse foi concretizado ao perceber as possibilidades que o caso dispunha, pois em suas entrelinhas existiam escolhas que levariam a rumos diferentes e isso poderia gerar discussões mais ricas e não programadas.

Para ser um bom caso, Alberton e Silva (2018) explicam que é necessário que as notas de ensino devem estar bem estruturadas de modo a orientar o professor na condução. A crítica 
está nesse ponto, tendo em vista que as notas de ensino eram pouco instrutivas de modo que as discussões não eram aprofundadas e direcionadas a reflexão. Além disso, as questões muito simples e mal formuladas foi um ponto, posteriormente, destacado pelos próprios alunos. Apesar da constatação prévia da fragilidade das questões, as mesmas foram testadas e atestouse que deveriam ser reformuladas, mas isso foi positivo na experiência considerando que provocou uma reflexão nos alunos ao ler e compreender o contexto do caso.

Enquanto papel assumido pelo professor, as pesquisadoras se prepararam para serem mediadoras da experiência e estimular a reflexão por meio de perguntas e não respostas. Assim, o caso fio repassado e segmentado com pontos importantes, momentos de intervenção e questões provocativas em torno da discussão embasadas na teoria.

\section{Fase 2 - Preparação dos discentes}

A preparação se inicia nas duas aulas que antecedem a aplicação do caso. Primeiramente, a sensibilização dos alunos é uma fase primordial para entusiasmá-los e esclarecer que será uma dinâmica diferente que necessita da participação ativa de todos. Nesse momento, a necessidade de leitura é enfatizada, destacando que é preciso que estejam aptos a compartilharem suas opiniões e criticidade quanto a situação apresentada.

$\mathrm{O}$ caso foi disponibilizado com antecedência de 15 dias para conclusão da leitura e reflexão das respostas. Aos alunos era solicitado que respondessem, individualmente, as 6 questões propostas pelas autoras do caso e as levassem respondidas no dia da aplicação. Na semana seguinte, que antecedia a aplicação do caso, foi explicada a dinâmica do método com explanações sobre a participação e pontuações associadas ao desempenho. Nesse momento, foi acordado que a atividade seria gravada para análise da aplicação da metodologia, cuja aceitação foi unânime.

\section{Fase 3 - A aplicação do caso}

No dia da aplicação, as pesquisadoras foram previamente a sala para preparar o local para interação e, após distribuir as cadeiras em grupos de 4 alunos, a entrada foi liberada. Os alunos foram divididos por numeração, com o intuito de separar os grupos de afinidades naturalmente formados. Os alunos se mostraram eufóricos e ansiosos para compartilhar suas respostas. Dessa forma, o plano de aula foi seguido à risca em tempo e em ações.

O papel a ser assumido aparece nesse momento, quando o aluno se torna protagonista da sua experiência, decide quando e como interagir e explicar aos demais o seu ponto de vista. A observação era primordial nesse momento, pois eles conversavam e refletiam sobre a 
percepção diferente de seus colegas. Alguns tentavam indagar as professoras sobre a dúvida, mas as pesquisadoras não se pronunciavam quanto a resposta, apenas contribuíam com outra pergunta ou direcionando a fala para outro aluno presente no mesmo grupo. Em alguns momentos, os alunos diziam que iriam mudar suas respostas (o que era permitido), visto que haviam compreendido de outra maneira após a discussão com o grupo.

Nesse contexto, vale ressaltar que a pergunta mais recorrente foi " $\mathrm{O}$ empreendedorismo contido no caso é por necessidade e ou por oportunidade?". Posteriormente a aplicação do caso, essa pergunta foi respondida por eles quando compreenderam que os conceitos existem para refletirmos, mas que na realidade do empreendedor as "caixinhas" que sistematizam o conteúdo podem se misturar e demostrar a real situação do momento, podendo esta ser diferente da situação do momento seguinte. Essa ressignificação foi concluída pelos alunos, sem intervenção, apenas mediação da distribuição de falas entre eles.

O aprendizado é perceptível, por vezes parece que o tempo é curto, mas é suficiente para consolidar a reflexão na ação e gerar estímulo para novas descobertas. O procedimento foi operacionalizado, sendo 30 minutos no pequeno grupo de 4 alunos, em seguida as pesquisadoras professoras explanaram pontos primordiais no caso em consonância com a teoria e, por fim, 60 minutos de discussão com toda a turma em um grande círculo. As pesquisadoras mediavam as discussões e davam a palavra para os alunos, pois alguns participavam mais.

Um episódio em especial merece ser destacado, um aluno compreendeu que uma personagem (a mãe) era causadora da desistência das protagonistas (as filhas), sendo isso contrário ao caso. Como o aluno vinha participando da discussão, compreendeu-se que houve uma assimilação errada por parte dele. Entretanto, as professoras pesquisadoras não precisaram interferir porque os próprios alunos começaram a dizer passagens do caso (sem estarem com ele impresso) que atestavam que a participação da personagem (mãe) não era primordial para a ação, mas era um apoio emocional e financeiro que não tinha poder de decisão. Isso comprovou que a metodologia proporciona o desenvolvimento dos alunos e a posição ativa diante de situações.

Ademais, o entusiasmo dos alunos para responderem aos questionamentos e, em alguns casos, as colocações tão estruturadas envolvidas em teorias fizeram com que as pesquisadoras percebessem que, enquanto professoras, por vezes, podem subestimar o potencial e a capacidade de atuar enquanto protagonista do seu próprio conhecimento devido à visão tradicional da educação passiva. Isso se deu em decorrência da ativa participação e agradecimentos pela experiência de aprendizado e colaboração, bem como pela compreensão da teoria em situações reais (ressignificação dos seus conhecimentos). 
O docente se depara com uma nova configuração, um novo local e uma nova maneira de agir, exigindo preparação e disposição para permanecer na metodologia. A mediação não desmerece o professor, enaltece sua condição de facilitador e o protagonismo do aluno necessários para construções mais efetivas dos saberes. A sensação sentida pelas professoras foi de transformação na educação e coerência com as novas necessidades da educação superior.

Ao final da experiência, os alunos pediram para compartilhar sua percepção sobre o método de caso para ensino. Eles relataram que o fato de poder vivenciar a experiência por meio do caso, os proporcionou uma visão mais ampla do que havia sido discutido em sala, além disso, explicaram que a mistura entre os colegas tinha sido muito interessante, pois puderam ver outras opiniões e se integrarem mais. De fato, os alunos relataram que mudaram suas opiniões a partir das visões dos colegas e dos questionamentos provocativos ditos pelas professoras pesquisadoras, enfim, afirmaram que se fossem responder novamente as 6 questões, responderiam de maneira diferente baseados em seus conhecimentos construídos de forma ativa e reflexiva.

A partir da aplicação do caso, as professoras pesquisadoras perceberam que são as condutoras das experiências dos alunos, mas que não possuem o controle sobre a reação de cada um deles. Nesse caso, a orientação para a autonomia e a postura ativa contribuem mais significativamente do que o derramamento desenfreado de conteúdos em caixinhas, o contato com a realidade transforma a experiência do docente e do discente, gerando um processo de ensino-aprendizagem mais efetivo. Fazendo mister destacar que, na experiência no ensino superior, uns três alunos foram embora, sendo necessária a reflexão: "Será que os discentes estão abertos para metodologias ativas de aprendizagem?".

\section{CONSIDERAÇÕES FINAIS}

Este capítulo se propôs a analisar o papel desempenhado pelo docente e pelo discente na nova configuração do Ensino Superior, a partir da aplicação da metodologia ativa Caso para Ensino, em uma instituição privada de ensino superior, no curso de graduação em Administração, dentro da disciplina de Empreendedorismo. Buscou-se fomentar uma reflexão crítica a respeito dos papéis assumidos, da ressignificação do conhecimento e da receptividade da experiência como prática de ensino no nível superior.

A urgência da transformação da educação superior, abandonando a exposição passiva de conteúdos engessados e assumindo a autonomia do aluno como gerador do seu conhecimento, 
é demonstrada nesse contexto analisado, a partir das experiências de aplicação de metodologias ativas de ensino.

O docente de carreira precisa enfrentar uma nova realidade de mudanças constantes e de um público discente desconectado com a tradicionalidade própria do método antigo de ensino. As novas metodologias representam a nova configuração necessária para atingir o interesse e incentivar os discentes a buscarem seu próprio aprendizado de maneira autônoma, colaborativa, criativa e efetiva, solucionando problemas, agindo a partir de desafios e refletindo para assimilação do conhecimento adquirido.

Nesse contexto, os papéis se transformam para proporcionar o ambiente adequado para geração de novas construções do saber. $\mathrm{O}$ docente assume o papel de mediador e incentivador da busca, reflexão e colaboração. O discente, por sua vez, torna-se protagonista e proporciona sua maior compreensão por meio de competências adquiridas no processo de ensinoaprendizagem.

$\mathrm{Na}$ verdade, não se deve correr na contramão do desenvolvimento. Os papéis mudam e a forma de aprender também, assim como tudo no mundo, a educação demonstra sua evolução. Cabem aos atores desse processo buscarem suas atuações e se moldarem às novas configurações, priorizando o conhecimento e a formação dos profissionais.

\section{REFERÊNCIAS}

ALBERTON, A.; SILVA, A. B. Como escrever um bom caso para ensino? Reflexões sobre o método. Revista de Administração Contemporânea, v. 22, n. 5, p. 745-761, 2018.

ARAÚJO, G. D. et al. Currículo e vínculos teoria-prática: reflexões no processo ensinoaprendizagem em um curso de graduação em Administração. Desenvolve Revista de Gestão do Unilasalle, v. 3, n. 2, p. 09-31, 2014.

BITTENCOURT, J. P. Arquiteturas pedagógicas inovadoras nos mestrados profissionais em administração. 2016. Tese (Doutorado). Universidade de São Paulo.

ESCRIVÃO FILHO, E.; RIBEIRO, L. R. C. Inovando no ensino de administração: uma experiência com a aprendizagem baseada em problemas (PBL). Cadernos EBAPE. BR, v. 6, n. SPE, p. 01-09, 2008.

FRACASSO, E. M. et al. Casa flor. Um caso de empreendedorismo em pequeno negócio. Revista de Administração e Inovação-RAI, v. 5, n. 3, 2008.

GABRIEL, A.; DA SILVA, J. S.; FREIRE, E. J. A utilização da investigação, do estudo dirigido e do estudo de texto como estratégias de ensino: um caso particular numa instituição de ensino superior (IES) no município de alta Floresta - MT. Pedagogia em Foco, v. 13, n. 9, p. 112-129, 2018. 
GAETA, C; MASETTO, M. Ofício de professor. In: . O professor iniciante no ensino superior: aprender, atuar e inovar. São Paulo: Senac São Paulo, 2013.

GONÇALVES, A. J.; CUNHA, J. L. L.; SALES, G. L. Concepção do fórum p\&rlv: avaliação formativa da aprendizagem. RENOTE-Revista Novas Tecnologias na Educação, v. 14, n. 1, 2016.

IKEDA, A. A.; VELUDO DE OLIVEIRA, T. M.; CAMPOMAR, M. C. O caso como estratégia de ensino na área de Administração. Revista de Administração, v. 41, n. 2, p. 147-157, 2006.

LESTINGE, S.; SORRENTINO, M. As contribuições a partir do olhar atento: Estudos do meio e a educação para a vida. Ciência \& Educação. Brasília, DF. 14, n. 3, p. 601-19, 2008.

LIMA, T. B.; SILVA, A. B. da. Difusão das perspectivas teóricas da aprendizagem na formação de administradores. Revista Iberoamericana sobre Calidad, Eficacia y Cambio em Educación, v. 11, n. 3, p. 5-30, 2013.

MACHADO, A. G. C.; CALLADO, A. A. C. Precauções na adoção do método de estudo de caso para o ensino de administração em uma perspectiva epistemológica. Cad. EBAPE.BR, Rio de Janeiro, v. 6, n. spe, p. 01-10, ago. 2008.

MASETTO, M. T. Docência universitária com profissionalismo: Competência pedagógica do professor universitário. São Paulo: Summus, 2012, p. 23-41.

NETO, J. O. R. et al. Aprendizagem baseada em problemas: o mito e a realidade. Cadernos UniFOA, v. 6, n. 16, p. 79-84, 2017.

O'NEIL, J.; MARSICK, V. Understanding action learning. Nova York: AMACOM; Div American MgmtAssn, 2007.

REAL, L. M. C.; MENEZES, C. Júri simulado: possibilidade de construção de conhecimento a partir de interações em um grupo. In: NEVADO, R. A.; CARVALHO, M. J. S.; MENEZES, C. S. (Orgs.). Aprendizagem em rede na Educação a Distância. Porto Alegre: Ricardo Lenz, 2007.

SALVADOR, A. B.; IKEDA, A. A. O uso de metodologias ativas de aprendizagem em MBA de marketing. Cadernos EBAPE.BR, v. 17, n. 1, p. 129-143, 2019.

SANTOS, G. T.; BASTOS, A. F. V.; COELHO, A. L. A. L. Contribuições do Seminário Dinâmico no processo de aprendizagem pela ótica dos graduandos de contabilidade da UFPB. Anais. XL ANPAD, Costa do Sauipe- BA, 2016.

SILVA, A. B.; SANTOS, G. T. D.; BISPO, A. C. K. A. The Comics as Teaching Strategy in Learning of Students in an Undergraduate Management Program. Revista de Administração Mackenzie, v. 18, n. 1, p. 40-65, 2017.

SILVA, R. V.; OLIVEIRA, E. M. As possibilidades do uso do vídeo como recurso de aprendizagem de aula do $5^{\circ}$ ano. Pesquisa em educação: Desenvolvimento, ética e responsabilidade social, 2010. 
SONAGLIO, A. L. B.; GODOI, C. K.; DA SILVA, A. B. Estilos de aprendizagem experiencial e aquisição de habilidades: um estudo com discentes de graduação em administração em instituições de ensino superior. Administração: ensino e pesquisa, v. 14, n. 1, p. 123-159, 2013.

SOUZA, N. A.; BORUCHOVITCH, E. Mapas conceituais: estratégias de ensino/aprendizagem e ferramenta avaliativa. Educação em Revista, v. 26, n. 3, p. 195-218, 2010 .

TOBIAS, O. P.; FALEIRO, F. S.; DE MELLO BRAGA, L. B. Proposta de aumento da eficácia e eficiência no processo de usinagem de eixos ferroviários. Revista Petra, v. 3, n. 1, 2017.

VERGARA, S. Constant. Repensando a relação ensino aprendizagem em administração: argumentos teóricos, práticas e recursos. Organizações \& Sociedade, v. 10, n. 28, p. 131-142, 2003.

YIN, R. K. Estudo de caso: planejamento e métodos. 5. ed. Porto Alegre: Bookman, 2015. 